\title{
Knowledge Sharing Enablers in Small Business Networks
}

\author{
Paula Hall, University of KwaZulu-Natal, South Africa \\ Debbie Ellis, University of KwaZulu-Natal, South Africa \\ (iD https://orcid.org/0000-0002-8464-6022 \\ Brian McArthur, University of KwaZulu-Natal, South Africa
}

\begin{abstract}
In an increasingly knowledge-based global economy, social capital and knowledge sharing, particularly amongst small business, have become critical sources of competitive advantage, but how can such knowledge sharing be enabled? The objective of this research was to explore the effect of knowledge sharing enablers on knowledge sharing in female small business networks. This research addresses the call for research into the antecedents of social capital. Specifically, trust, social identity, social media usage, and shared goals were included in the conceptual model for the study. Together these social capital enablers were found to be significant predictors of knowledge sharing behaviour, although unique contributions varied. The research contributes to the growing body of literature on the dimensions of social capital and how they affect knowledge management, and is of use to practitioners involved in supporting female entrepreneurial networks.
\end{abstract}

\section{KEYWORDS}

Female Entrepreneurs, Female Networks, Inter-Organisational Networks, Knowledge Sharing Behaviour, Shared Goals, Social Capital, Social Identity, Social Media Usage, Trust

\section{INTRODUCTION}

With increased global and local competition, the ability of small businesses to share knowledge can be a source of competitive advantage (Jashapara, 2011). The question is, what enables this knowledge sharing? The move towards a knowledge-based economy has placed a premium on the way small businesses assimilate and share that knowledge (Blankley \& Booyens, 2010; Powell \& Snellman, 2004), especially in an emerging economy like South Africa. Women have been disproportionally affected by the COVID-19 pandemic, adding to South Africa's structural unemployment and the "feminization of poverty" (Parry \& Gordon, 2021, p. 797). Female entrepreneurs in Africa are essential for economic growth, yet face resistance due to complex cultural norms (Ojong, Simba, \& Dana, 2021, p. 237) and therefore need additional support and the connections networks provide (van Blokland, 2018). Female business owners have less opportunity to share knowledge through networking than men do (Dawa \& Namatovu, 2015; Herrington \& Kew, 2016; Oke, 2013), even though women tend to be more open to knowledge sharing than men (Connelly \& Kelloway, 2003). Networks dominated by men do not provide collaborative, welcoming support for female entrepreneurs 
(van Blokland, 2018). Women only entrepreneurial networks have emerged in response to the need to share knowledge among female entrepreneurs facing similar problems, facilitated by the ease of creating virtual networks (Cao, Guo, Liu, \& Gu, 2015; Shanmuga \& Sakthi, 2015).

In a systematic review of gender and knowledge management, Heisig and Kannan (2020) conclude that gender has been overlooked in the knowledge management research, with only seven papers found in knowledge management journals. Much of the research into inter-organisational knowledge sharing has focused on industry-specific relationships or formal collaborations (Agostini, Nosella, Sarala, Spender, \& Wegner, 2020; Van Der Meer, 2014), rather than small business or entrepreneurial networks. Further, the focus on female small businesses in a developing economy underscores their importance for employment, equity and economic growth (Ekpe, Mat, \& Ekpe, 2015). With the rise of emerging economies considered a mega-trend, research in this area is particularly pertinent (CanoKollmann, Hannigan, \& Mudambi, 2018; Olanrewaju, Hossain, Whiteside, \& Mercieca, 2020) and is likely to increase post-pandemic.

Previous research has largely ignored individual factors such as gender, when considering knowledge sharing enablers (Marouf \& Khalil, 2015). The prevalence of social media networks means these networks exist at least partially online, especially in the time of Covid-19, broadening the geographic scope of membership and facilitating essential knowledge of global issues (CanoKollmann et al., 2018; Haeffele, Hobson, \& Storr, 2020; Olanrewaju et al., 2020). The objective of this research is to investigate knowledge sharing enablers in female small business networks, filling the gap at the intersection of female entrepreneurs in developing economies, business networks and knowledge sharing.

\section{FEMALE SMALL BUSINESS INTER-ORGANISATIONAL NETWORKS}

Small business networks are complex yet fruitful inter-organisational systems that differ in character and networking patterns from other types of networks (Agostini et al., 2020). Further, these networks offer more support than intra-organisational networks (S. Chen, Duan, Edwards, \& Lehaney, 2006; Nguyen, Nham, Froese, \& Malik, 2019). While networks are important for success in small business start-ups, knowledge transfer between small businesses is under-researched (Massaro, Moro, Aschauer, \& Fink, 2019). Oke (2013) showed that in developing countries, female entrepreneurs can use networks to improve the flow of information and gain access to knowledge and pool resources. Entrepreneurial networks have been shown to differ based on gender (Heisig \& Kannan, 2020) with women's networks generally less diffuse and comprised of people who know each other well, which limits access to new, competitively helpful information. This, coupled with lower levels of mobility and greater spatial constraints in women's daily activity patterns, (Hanson \& Blake, 2009) suggests that knowledge sharing behaviors may be different in women's networks. Therefore, further research into female small business networks is warranted (Hanson \& Blake, 2009).

Inkpen and Tsang (2016) identified future research opportunities as involving specific network types, especially in newer virtual networks. Likewise, Agostini et al. (2020) recommended research into inter-organisational knowledge sharing in SMEs, while Oke (2013) recommended research into social networking determinants for female entrepreneurs. This research therefore aims to investigate knowledge sharing enablers in inter-organisational, SME networks specifically for female entrepreneurs.

\section{KNOWLEDGE SHARING}

Knowledge sharing behaviour (KSB) implies a reciprocal process where knowledge is donated (or given) and collected (or received) (Van Den Hooff \& De Ridder, 2004). Knowledge sharing within and between organisations, improves organisational innovation and performance (van Wijk, Jansen, \& Lyles, 2008), specifically by reducing costs and growing sales (Marouf \& Khalil, 2015). Knowledge 
sharing empowers entrepreneurs to deal with business complexity and uncertainty (Mc Manus, Ragab, Arisha, \& Mulhall, 2016), and supports the conversion of social, tacit knowledge that can be gained in a social network, into individual, private knowledge that can be used by an entrepreneur (Ma \& Chan, 2014). Agostini et al. (2020) call for finer-grained knowledge management research on small and medium enterprises (SMEs) contending that current research in this context is very broad. Lefebvre, Sorenson, Henchion, and Gellynck (2016) argue that there is a lack of research in determining knowledge sharing enablers, especially research at the network level. This research therefore aims to address these calls.

\section{Enabling Conditions for Knowledge Sharing}

Choo and de Alvarenga Neto (2010) identified four sets of enablers that allow knowledge processes to gain traction (social/behavioral, cognitive/epistemic, information systems/management and strategic/ structure). The Social/Behavioral category includes factors such as trust and social identity, related to relationships and interactions prevalent in informal business networks (Choo \& de Alvarenga Neto, 2010). The Cognitive/Epistemic group relates to conditions required for shared spaces and goals being considered as an important enabling factor in networks (Choo \& de Alvarenga Neto, 2010). The Information Systems group relates to information and communication technologies such as social networks, that enable knowledge sharing (Choo \& de Alvarenga Neto, 2010). Finally, the Strategy/ Structure group deals with support for knowledge sharing, in terms of providing the structure and functioning for example, of the network. There is a close relationship between the afore-mentioned enablers and those implicit in social capital theory, which is reviewed next.

\section{SOCIAL CAPITAL THEORY}

Social capital derives from networks of relationships that allow network members to share and mobilise knowledge (Ganguly, Talukdar, \& Chatterjee, 2019; Nahapiet \& Ghoshal, 1998). Spender et al (2017) determined that social capital empowered start-ups through knowledge transfer. Nahapiet and Ghoshal (1998) were the first to divide the concept of social capital into three dimensions: relational, cognitive and structural, and most subsequent studies on social capital and knowledge sharing are based on these (Ganguly et al., 2019; Han, Yoon, \& Chae, 2020; Nguyen et al., 2019). Relational social capital develops from personal relationships and includes trust and social identity as key facets (Nahapiet \& Ghoshal, 1998). Both factors are considered as knowledge sharing enabling factors for this research, thus relational social capital is conceptualised as a two-dimensional construct. The relational dimension is equivalent to the social/behavioral group of factors identified above by Choo and de Alvarenga Neto (2010). The cognitive dimension provides systems of meaning among members of networks, as per the cognitive/epistemic group devised by Choo and de Alvarenga Neto (2010). Cognitive social capital is conceptualised in terms of the shared goals dimension (Nahapiet \& Ghoshal, 1998) for this paper. The final facet, structural social capital refers to the connections between members in the form of social or network ties, as would be evidenced in an online social media network (Choo $\&$ de Alvarenga Neto, 2010; Ganguly et al., 2019). Thus, there are four factors from the dimensions of social capital forming the knowledge sharing enablers used in this paper: Social media networks in the structural dimension; trust and social identity in the relational dimension; and shared goals in the cognitive dimension.

\section{DEVELOPMENT OF THE CONCEPTUAL FRAMEWORK}

KSB is the dependent variable in this research. Derived from social capital theory, each of the KSB enablers is an independent variable for the study and is expanded on below. 


\section{Social Media Usage - Knowledge Sharing Enabler in the Structural Dimension of Social Capital}

Social media in the context of knowledge sharing is a way for people to easily share knowledge collectively, increasing social capital (Majchrzak, Faraj, Kane, \& Azad, 2013; Olanrewaju et al., 2020). Jennex and Bartczak (2015) define social networks as including both formal and informal networks for the transfer of knowledge. S. Chen et al. (2006) explained that explicit and tacit knowledge require a channel to facilitate transfer across organisational boundaries. These channels are most suitably manifested as electronic social networks, relying on information technology and allowing a network to be closer in time and space (Mc Manus et al., 2016; Tohidinia \& Mosakhani, 2010). This is particularly relevant with social distancing due to COVID-19 limiting physical social networking (Haeffele et al., 2020). More research has been called for concerning social media as a platform for knowledge sharing (Lefebvre et al., 2016) and in the context of developing counties (Olanrewaju et al., 2020). Jenkins-Guarnieri, Wright, and Johnson (2013) conceptualise social media usage as the degree to which social media is integrated into people's routines and how much importance they place on their connections to users. Oke (2013) found that female entrepreneurs' social networks improved their success. This research therefore investigated the relationship between the female network members use of their network's social media and their knowledge sharing behavior, in the first hypothesis:

$\mathrm{H}_{1}$ : Social media use has a positive effect on KSB in female SME networks.

\section{Trust - Knowledge Sharing Enabler in the Social Dimension of Social Capital}

Trust in relation to knowledge sharing is commonly divided into benevolence-based trust, which stems from belief in the integrity of others, and competency-based trust, based on the belief in the ability of others (Levin \& Cross, 2004; Paroutis \& Al Saleh, 2009; Usoro, Sharratt, Tsui, \& Shekhar, 2007). Although trust is a multi-faceted concept, in terms of trust between female members of a network, it is conceptualised as the expectation of cooperation and honesty between members allowing mutual confidence in each other and based on benevolence and competence (Levin \& Cross, 2004). The issue of trust in knowledge sharing has been raised by several researchers (e.g. S. Chen et al., 2006; Han et al., 2020; Massaro et al., 2019). A recent review of the research on inter-organisational knowledge transfer demonstrated the necessity for trust in sharing knowledge in networks (Battistella, De Toni, \& Pillon, 2016). Trust has also been identified as one of the important elements of the relational dimension in social capital theory (Inkpen \& Tsang, 2005). For female members of an SME network to share knowledge, it is proposed in this study that trust is an enabling factor for knowledge sharing behavior. This leads to the second hypothesis:

$\mathrm{H}_{2}$ : Trust has a positive effect on KSB among members of female SME networks.

\section{Social Identity - Knowledge Sharing Enabler in the Social Dimension of Social Capital}

Ridgeway and Smith-Lovin (1999), found that gender-identity is closely related to social identity. Shared social identity has been conceptualised as a pre-requisite to inter-organisation sharing of knowledge (Nieminen, 2005). In this paper, the construct of social identity refers to the shared meaning that group members derive from belonging to a network (Mariotti, 2005). Having a shared social identity lowers the cost of communication while increasing co-operation and opportunity for knowledge sharing (Nahapiet \& Ghoshal, 1998; Nieminen, 2005). Shared understanding is required of the relationship between sender and receiver firms in knowledge transfer while a shared professional identity increases trust and knowledge sharing between organisations (Nieminen, 2005). The relationship between social identity and knowledge sharing behavior leads to the third hypothesis: 
$\mathrm{H}_{3}$ : Shared identity has a positive effect on KSB of female members of SME networks.

\section{Shared Goals - Knowledge Sharing Enabler in the Cognitive Dimension of Social Capital}

This factor refers to the common purpose, or vision, that members of a female network have - a cohesive force allowing knowledge sharing and facilitating cooperation among members (Chow \& Chan, 2008; Inkpen \& Tsang, 2005). The premise is that network members will act in their collective self-interest if they share goals to their mutual benefit (Leana \& Pil, 2006; Tsai \& Ghoshal, 1998). Connelly and Kelloway (2003) found that females associate knowledge sharing with social interaction, one of the goals of female networks. Shared goals and vision have also been shown to improve the quality and quantity of knowledge sharing (Chiu, Hsu, \& Wang, 2006; Darvish \& Nikbakhsh, 2010). One study that considered shared goals as part of the cognitive dimension of social capital in an interfirm network was conducted by Y.-H. Chen, Lin, and Yen (2014) who concluded that shared goals improve knowledge sharing through the mediating variable of inter-organisational trust. However, the research was on supply chains, which are a very different type of network to entrepreneurial networks. With little research into this specific context of small business networks, the fourth hypothesis is:

$\mathrm{H}_{4}$ : Shared goals have a positive effect on knowledge sharing behavior of female SME networks.

The four hypotheses presented above are shown in the conceptual framework below.

Figure 1. Conceptual model

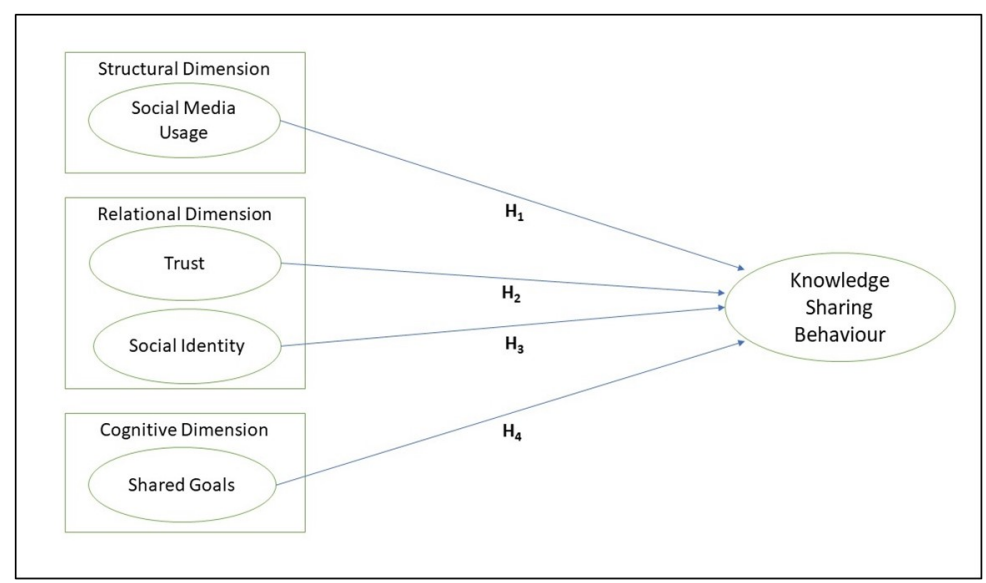

\section{RESEARCH METHODOLOGY}

Data was collected by means of a self-administered questionnaire, since this tool is ideal for collecting behavioral and attitudinal, descriptive data (Sekaran \& Bougie, 2016), sent to the membership of three South African female SME networks, all of which have formal social networks. The networks have their home base in the region of KwaZulu Natal but allow membership from anywhere in South Africa. The networks are formally organised by committee and have a leader who distributed the questionnaire to their members. A usable sample of 117 was achieved. 


\section{Measures}

The scales used to measure the variables were previously validated and tested, in relation to knowledge sharing and communities. They were adapted to ensure clarity that the questions related to membership in the respondents' network.

An established scale to measure $K S B$, developed by Van den Hooff, Elving, Meeuwsen, and Dumoulin (2003), was selected because it was created specifically to measure knowledge sharing in communities that have a virtual presence and demonstrated reliability with a Cronbach's Alpha of 0.87 . The scale includes knowledge donating behaviour and knowledge collecting behavior, given that sharing implies a two-way reciprocal transfer of knowledge (Nguyen et al., 2019).

The trust scale was based on the scale developed by Van den Hooff et al. (2003) to measure benevolent and cognitive trust in a knowledge sharing community. The Cronbach Alpha was 0.76 indicating a high level of inter-item reliability in the trust construct (Van den Hooff et al., 2003).

Chiu et al.'s (2006) social identity scale formed the basis of the scale for this paper, for which a high level of inter-item reliability was found (0.90) (Chiu et al., 2006).

Maree's (2017) integration into social routines scale dimension was most relevant to this study to measure social media usage with a Cronbach's Alpha of 0.77 reported.

Chiu et al.'s (2006) measure of shared goals with a Cronbach's alpha of 0.88 was deemed a reliable measure for this study.

\section{Data Analysis}

Data about each knowledge enabling factor in the questionnaire, tested with a series of 5-point Likert items from $1=$ strongly disagree to $5=$ strongly agree, was summated and the composite scores analysed using descriptive statistics. To determine the predictive capacity of the enablers, a multiple regression analysis was conducted. Assumptions for regression were checked and while some correlations between the enablers were high, they were less than the 0.9 cutoff (Warner, 2012) and the Tolerance and VIF collinearity diagnostics indicated suitability for regression (Tolerance $>0.1$ and VIF $<10$ ) (Pallant, 2010). Assumptions related to sample size, outliers, normality, linearity, homoscedasticity and independence of residuals (Pallant, 2010) were all checked and found not to be violated.

\section{Reliability and Validity of the Measures}

Table 1 presents the Cronbach alphas for each scale, with most proving reliable and internally consistent.

Table 1. Scale Cronbach Alphas

\begin{tabular}{|l|l|}
\hline Variable/Construct & Cronbach's alpha \\
\hline Knowledge sharing behaviour & 0.90 \\
\hline Trust & 0.90 \\
\hline Social Identity & 0.92 \\
\hline Social media usage & 0.77 \\
\hline Shared goals & 0.64 \\
\hline
\end{tabular}

The exception was the shared goals construct, with a Cronbach alpha of marginally less than the acceptable level of 0.7 (Sekaran \& Bougie, 2016). Based on the theoretical and past research support for this construct and the marginally acceptable Cronbach alpha, the variable was retained in the study for further analysis. 
Content validity by means of questionnaire verification (Koonin, 2014) was ensured through the pretest of the questionnaire by the network organisers. In addition, each construct was tested using a previously validated scale, as discussed above, thus ensuring that the questionnaire measured what was intended (Koonin, 2014).

\section{RESULTS AND DISCUSSION}

Table 2 presents the respondent profile. Most respondents had businesses in the service sector (65.2\%) and employed less than ten people $(71,8 \%)$. The majority of members $(93 \%)$ had obtained a tertiary education.

Table 2. Respondent profile

\begin{tabular}{|l|l|l|l|l|l|l|}
\hline $\mathbf{N = 1 1 7}$ & \multicolumn{4}{|l}{ Frequencies (percentages) } & Missing \\
\hline Age & $21-30$ & $31-40$ & $41-50$ & $51-60$ & $>60$ & \\
\hline & $7(6 \%)$ & $25(21.4 \%)$ & $48(41 \%)$ & $30(25.6 \%)$ & $7(6 \%)$ & 0 \\
\hline $\begin{array}{l}\text { Years in } \\
\text { Business }\end{array}$ & $1-10$ & $11-20$ & $21-30$ & $31-40$ & Over 40 & \\
\hline & $27(23.3 \%)$ & $37(31.9 \%)$ & $32(27.6 \%)$ & $18(15.5 \%)$ & $2(1.7 \%)$ & 1 \\
\hline $\begin{array}{l}\text { Highest } \\
\text { Education }\end{array}$ & $\begin{array}{l}\text { Secondary school } \\
\text { not completed }\end{array}$ & $\begin{array}{l}\text { Secondary school } \\
\text { completed }\end{array}$ & $\begin{array}{l}\text { Tertiary } \\
\text { completed }\end{array}$ & $\begin{array}{l}\text { Post-graduate } \\
\text { completed }\end{array}$ & & \\
\hline & $1(0.9 \%)$ & $6(5.2 \%)$ & $54(47.4 \%)$ & $55(46.6 \%)$ & & 1 \\
\hline
\end{tabular}

More than half $(54.5 \%)$ of the respondents have been members of their network for 3 or less years, with $73.6 \%$ having been members for less than 5 years. The network membership size ranged between 500 and 2500, with the largest one also being the oldest, having been established in 1995 . The other two networks were established in 2000 and 2005. Most members $(64.1 \%)$ belonged to just the one main network. There were several smaller local networks the members belonged to, in addition to being members of the main three networks considered in this research.

One of the networks had a younger age profile, with $34 \%$ of respondents under 40 , compared to $24 \%$ and $17 \%$ for the other two networks, with years of experience similarly distributed. The network with younger members also shared a similar reason for joining the network - advice, mentoring and knowledge (68\%) illustrating the need for learning and mentorship by younger entrepreneurs compared to older members who cited leads and sales contacts as reasons for joining. However, factors such as education level, business sector and number of employees were similar across all networks. Despite the differences between the networks, knowledge sharing behaviour was largely the same between the networks with means of mean 3.57, 3.93, 3.76. Therefore, analysis continued on an individual member basis, as per the objectives of the research.

\section{The Extent and Nature of Knowledge Sharing}

The KSB scale was shown to be reliable, consistent with the scale developed by Van den Hooff, which was made up of knowledge donating and knowledge collecting behaviour (Van Den Hooff \& De Ridder, 2004). Table 3 presents the results for this construct.

KSB was found to be positive among network members, in both knowledge donating ( $\mathrm{M}=3.82$, $\mathrm{SD}=0.83)$ and knowledge collecting $(\mathrm{M}=3.7, \mathrm{SD}=0.89)$ behaviours. A score of 5 represents a high level of these behaviours while 1 represents a low level. The reasons for high knowledge collecting 
Table 3. Knowledge Sharing Behaviour

\begin{tabular}{|l|l|l|}
\hline & Mean & Std Dev. \\
\hline Knowledge Sharing Behaviour & $\mathbf{3 . 7 5}$ & $\mathbf{0 . 8 4}$ \\
\hline When I've learned something new, I tell the other members of my network about it & 3.8 & 1.03 \\
\hline I tell the other members of my network what I know, when they ask me about it & 3.5 & 1.11 \\
\hline I tell the other members of my network about my skills, when they ask me about it & 4.11 & 0.99 \\
\hline Knowledge donating behaviour & 3.82 & 0.83 \\
\hline When they've learned something new, other members of my network tell me about it & 4.15 & 0.96 \\
\hline I ask other members of my network what they know when I need particular knowledge & 3.31 & 1.11 \\
\hline The other members of my network tell me what they know, when I ask them about it & 3.62 & 1.15 \\
\hline The other members of my network tell me about their skills, when I ask them about it & 3.71 & 1.03 \\
\hline Knowledge collecting behaviour & 3.70 & 0.89 \\
\hline
\end{tabular}

behaviour is self-evident, as the knowledge collector is the party gaining from the transfer for of knowledge. More interesting is that knowledge donating behaviour actually scored higher than knowledge collecting behaviour.

\section{The Knowledge Sharing Enablers}

Table 4 presents the descriptive statistics for the 4 enabler constructs including the items and composite variables.

Trust among members and in their network was relatively high $(\mathrm{M}=3.82, \mathrm{SD}=0.83)$. Social identity, along with trust, make up the relational element of social capital. Results revealed members have a relatively high degree of social identity with their network $(\mathrm{M}=3.67, \mathrm{SD}=1.02)$ and felt strong bonds with each other and feelings of togetherness and closeness. These relational element results were consistent across all three networks irrespective of years of membership and age.

The results show that, although members enjoy checking their network's Facebook account $(\mathrm{M}=3.73, \mathrm{SD}=1.18)$, they are less likely to make Facebook part of their daily routine $(\mathrm{M}=3.11$, $\mathrm{SD}=1.44)$ nor respond to content posted there $(\mathrm{M}=2.96, \mathrm{SD}=1.6)$, suggesting that members' social media usage on Facebook is passive. This demonstrates a lack of knowledge sharing over this social media platform and may either show that network members share much of their knowledge in the real world, as opposed to online, or that they use another platform, such as LinkedIn. Previous studies found social media facilitates KSB in a virtual network (S. Chen et al., 2006; Majchrzak et al., 2013). Contrary to expectations, social media usage was lowest in the network which had the lowest age distribution (mean 3 compared to the other networks 3,6 and 3,3). Social media usage was also lowest among members who had been members of the network for less than a year (2.9). A preference of the network members for in-person social networking is likely to decrease due to social distancing measures resulting from COVID-19 (Haeffele et al., 2020). The relatively high standard deviations indicate higher polarisation of responses and more research is needed to understand the underlying reasons for these responses.

Shared goals represent the cognitive dimension of social capital in this study. This scale had a relatively low Cronbach Alpha (0.64) therefore the results are discussed here but are not as reliable as the other knowledge enablers. Members agreed that they enjoyed helping each other as a shared value and that they shared the same goal of learning from each other. Interestingly, there were mixed opinions on whether members share the goal of helping each other solve professional problems, with as many members highly agreeing as those who highly disagreed. This is perhaps explained by $\mathrm{Li}$ 
Table 4 Knowledge Sharing Enablers

\begin{tabular}{|c|c|c|}
\hline & Me a n & Std Dev. \\
\hline Trust in network & 3.33 & 1.05 \\
\hline Other members of this network help me when I have a problem concerning my business & 3.33 & 1.29 \\
\hline I can rely on the other members of this network to support me in my business & 3.26 & 1.15 \\
\hline I can count on the other members of this network to do what they say & 3.47 & 1.06 \\
\hline I have faith in the skills of the other members of this network & 3.82 & 1.01 \\
\hline Social Identity & 3.67 & 1.02 \\
\hline I feel a bond with the other members of my network & 3.82 & 1.01 \\
\hline I am proud to be a member of my network & 3.42 & 1.24 \\
\hline I have a feeling of togetherness or closeness in my network & 3.88 & 1.14 \\
\hline I have a strong positive feeling toward my network & 3.55 & 1.17 \\
\hline Social Media Usage & 3.31 & 1.10 \\
\hline I enjoy checking my network's Facebook account & 3.73 & 1.18 \\
\hline Using Facebook is part of my everyday routine & 3.11 & 1.44 \\
\hline I would be disappointed if I could not use Facebook at all & 3.43 & 1.52 \\
\hline I respond to content that my network and others share using Facebook & 2.96 & 1.60 \\
\hline Shared Goals & 3.48 & 0.94 \\
\hline Members of my network share the goal of helping others solve their professional problems & 3.23 & 1.46 \\
\hline Members of my network share the same goal of learning from each other & 3.48 & 1.16 \\
\hline Members of my network share the same value that helping others is pleasant & 3.72 & 1.06 \\
\hline
\end{tabular}

(2005, p. 93) who states that shared vision is strong intra-organisationally, but is harder to maintain between organisations, such as SME networks.

To investigate the effects of the knowledge sharing enablers on KSB a regression was used where the measures for the enablers were treated as independent variables while KSB was treated as a dependent variable. Table 5 shows these results:

Table 5. Knowledge Sharing Enablers Correlation with KSB

\begin{tabular}{|c|c|c|c|c|}
\hline Variable & $\mathrm{R}$ & R Square & Adjusted R Square & $\begin{array}{l}\text { Std. Error of the } \\
\text { Estimate }\end{array}$ \\
\hline Trust & $.711^{\mathrm{a}}$ & .506 & .501 & .58987 \\
\hline Social Identify & $.768^{\mathrm{a}}$ & .590 & .586 & .53724 \\
\hline Social Media Usage & $.534^{\mathrm{a}}$ & .285 & .279 & .70931 \\
\hline Social Identity & $.728^{\mathrm{a}}$ & .529 & .525 & .57559 \\
\hline Overall Social Capital & $.786^{\mathrm{a}}$ & .617 & .614 & .51892 \\
\hline
\end{tabular}


Results provide strong support for the effect of social capital on KSB. The total variance in KSB explained by the four enabling factors together was $65.5 \%, \mathrm{R}^{2}=.565(\mathrm{~F}=53.303 ; \mathrm{p}<.001)$. Social identity had the greatest unique effect on KSB ( std $\mathrm{B}=.415 ; \mathrm{p}<.001)$ followed by shared goals (std $\mathrm{B}=.313 ; \mathrm{p}<.05)$. While exhibiting a fairly high correlation with KSB, trust's unique effect on KSB was not significant ( $\operatorname{std} \mathrm{B}=.149 ; \mathrm{p}=0.134$ ). Similarly, social media usage did not have a significant unique effect on KSB (std B $=.006 ; \mathrm{p}=0.946$ ).

These results suggest that of the four enablers, social identity was the best predicter of KSB among members. These results support and extend Chiu et al.'s (2006) findings beyond virtual communities. A significant positive relationship between social ties and knowledge sharing intention was also found by I. Y. Chen, Chen, and Kinshuk (2009) in a virtual learning community. Again, this study was only in a virtual community. Given that an aspect of social identity is based on gender by itself (Durbin, 2011), this could explain why the measure of social identity scored highly. Social identity is clearly a significant part of the success of female networks in terms of KSB.

The results confirm the hypothesis that the more members share goals, the higher their KSB. This element of social capital has been positively associated with KSB in multiple studies (Bautista \& Bayang, 2015; Chiu et al., 2006; Chow \& Chan, 2008; Darvish \& Nikbakhsh, 2010; Lefebvre et al., 2016) although many of them were in intra-organisational settings. Y.-H. Chen et al. (2014) concluded that shared goals in inter-firm networks improve knowledge sharing because shared goals improve communication and motivation, increasing trust, and then knowledge sharing.

Related to trust, the results support those of Rhodes, Hung, Lok, Lien, and Wu (2008) who found that a trust culture was the least important of the factors they considered in promoting knowledge sharing, nevertheless a positive relationship was still found. It is possible that trust did not have a significant unique effect on KSB because of the high level of overlap (Pallant, 2010) with social identity which is also a relational social capital variable. The correlation between trust and social identity was 0.809 . This research confirms the significant effect of social identity on KSB and the strong relationship between social identity and trust, as relational enablers, in the context of female SME networks, where female entrepreneurs are voluntary members of these open networks.

Although a positive correlation between social media usage and KSB was found, it did not have a significant unique contribution to the variance in KSB, contrary to Muwanga-Zake and Herselman (2017) finding that Facebook was used for interfirm knowledge sharing, The younger female entrepreneurs sampled had the lowest Facebook usage, despite the same age group being the highest Facebook users in South Africa in 2020 (Statistica, 2021), suggesting this was not a generational phenomenon.

\section{IMPLICATIONS}

Based on the results, the following recommendations can be made for the various stakeholders, followed by research implications from a theoretical perspective.

\section{Recommendations for Network Organisers}

Organisers of the female networks should support the knowledge enablers which significantly affect KSB given the link between knowledge sharing and SME organisational performance (Easterby-Smith, Lyles, \& Tsang, 2008; Lefebvre et al., 2016). Usually, shared vision is strong intra-organisationally, and is harder to maintain between organisations, such as SME networks ( $\mathrm{Li}, 2005)$, however the members of these female SME networks had relatively high levels of shared goals. Network members indicated altruistic motives for their shared goals and values, organisers should leverage this by providing forums to promote members willingness to solve professional problems. Formal mentorship programs are recommended, especially for the younger members who cited this as a reason for joining the network. Post pandemic, the organisers should promote explicit virtual knowledge sharing through expertlocator systems, online workshops and skill-based cross-training (Becerra-Fernandez \& Sabherwal, 
2010). Organisers can leverage the social capital and network effects for practical benefits such as access to funding and collaborations (van Blokland, 2018).

\section{Recommendations for Government and Sponsors}

Government, NGOs, and corporate sponsors interested in developing female entrepreneurship are recommended to invest in knowledge sharing networks. Given the effects of knowledge sharing and SME performance (Easterby-Smith et al., 2008; Lefebvre et al., 2016), this investment should translate into good business performance in the SMEs, thereby giving impetus to economic growth and community upliftment. This is particularly important given the economic situation in South Africa, worsened by the pandemic and civil unrest. The importance of networking and socialisation for knowledge sharing among entrepreneurs provides an ideal platform for a mutually beneficial relationship with corporate sponsors. These could be virtual given current restrictions on events. SME development agencies are also recommended to provide infrastructure for skills sharing and sponsorship of networking events for knowledge sharing.

\section{Recommendations for Female Entrepreneurs}

Female entrepreneurs would benefit from joining a women-only network, given the high level of KSB, especially knowledge donating behaviour displayed by members. There are well established structural differences between male and female networks (Upton, Broming, \& Upton, 2015) that mean women-only networks provide more support to female entrepreneurs (van Blokland, 2018). By becoming a member of such a network, they could benefit from the high level of trust and desire to help each other. Interactions between network members facilitate business development and enhance success and innovation, a primary goal of business owners (Agholor, Smith, Akeem, \& Seriki, 2015; Spender, Corvello, Grimaldi, \& Rippa, 2017).

\section{Research Implications}

The relationship Nieminen (2005) found between trust and social identity was confirmed in this research, where trust did not significantly affect KSB on its own. Future research could investigate how trust promotes social identity within SME networks. A recommendation for further research is to determine if there is a shift towards increased KSB online through social media, in the context of COVID-19 where functioning online has become paramount. Such research should include the full spectrum of social media platforms such as Instagram and LinkedIn, to determine their usage by, and influence on KSB in female SME networks. Research could also focus on other elements of structural capital such as social interaction ties, measuring the strength of network ties, which have been found to improve KSB (Chiu et al., 2006; Darvish \& Nikbakhsh, 2010).

Research could also be extended to include shared language and culture. Although Darvish and Nikbakhsh (2010) and Chiu et al. (2006) state that this has typically been found to be more prevalent and important intra-organisationally, this may be a relevant factor in a culturally and language diverse country such as South Africa. As networks develop and mature, they may develop a common language and a culture of their own, at which time research into this and KSB would also be beneficial. Finally, research comparing women-only networks to mixed or male-dominated networks will strengthen support for networks specifically designed for female entrepreneurs.

\section{CONCLUSION}

This paper contributes to the body of knowledge by testing the effects of social capital on knowledge sharing between female entrepreneurial firms in a SME network. The results of this study confirm the more members identify with their network and share goals, the greater the extent of their KSB. Although trust on its own does not affect KSB, its relationship with social identity indicates that it is important in KSB but needs more research. Equally important were the findings that were not expected. 
Although social media usage was found to be moderately related to KSB, the results show that social media usage was lower and more passive than expected. This may be useful for the organisers of the networks who may be concentrating too much on the social media aspects using Facebook as a platform for their networks. Of practical relevance, the KSB evidenced in SME networks implies that there are significant benefits for entrepreneurs in joining networks. In a post-pandemic emerging economy like South Africa, where women have borne the brunt of the effects of rising unemployment, support for entrepreneurship is more essential than ever. Female small business networks provide this support, increase social capital and share knowledge needed for success. 


\section{REFERENCES}

Agholor, E. D., Smith, W., Akeem, A. O., \& Seriki, I. I. (2015). Challenges faced by women entrepreneurs and strategies adopted by women entrepreneurs to ensure small business success in Nkonkobe Municipality. The South African Journal of Economics, 6(1), 37-49.

Agostini, L., Nosella, A., Sarala, R., Spender, J. C., \& Wegner, D. (2020). Tracing the evolution of the literature on knowledge management in inter-organizational contexts: A bibliometric analysis. Journal of Knowledge Management, 24(2), 463-490. doi:10.1108/JKM-07-2019-0382

Battistella, C., De Toni, A. F., \& Pillon, R. (2016). Inter-organisational technology/knowledge transfer: A framework from critical literature review. The Journal of Technology Transfer, 41(5), 1195-1234. doi:10.1007/ s10961-015-9418-7

Bautista, R. G., \& Bayang, M. A. (2015). Social Network, Social Trust and Shared-Goals towards OrganizationalKnowledge Sharing. American Journal of Educational Research, 3(5), 662-667.

Becerra-Fernandez, I., \& Sabherwal, R. (2010). Knowledge Management Systems and Processes. M.E. Sharpe, Inc.

Blankley, W., \& Booyens, I. (2010). Building a knowledge economy in South Africa. South African Journal of Science, 106(11/12), 1-6. doi:10.4102/sajs.v106i11/12.373

Cano-Kollmann, M., Hannigan, T. J., \& Mudambi, R. (2018). Global innovation networks-organizations and people. Journal of International Management, 24(2), 87-92. doi:10.1016/j.intman.2017.09.008

Cao, X., Guo, X., Liu, H., \& Gu, J. (2015). The role of social media in supporting knowledge integration: A social capital analysis. Information Systems Frontiers, 17(2), 351-362. doi:10.1007/s10796-013-9473-2

Chen, I. Y., \& Chen, N.-S., \& Kinshuk. (2009). Examining the factors influencing participants' knowledge sharing behavior in virtual learning communities. Journal of Educational Technology \& Society, 12(1), 134-148.

Chen, S., Duan, Y., Edwards, J. S., \& Lehaney, B. (2006). Toward Understanding Inter-Organizational Knowledge Transfer Needs in SMEs: Insight from a UK Investigation. Journal of Knowledge Management, 10(3), 6-25. doi:10.1108/13673270610670821

Chen, Y.-H., Lin, T.-P., \& Yen, D. C. (2014). How to facilitate inter-organizational knowledge sharing: The impact of trust. Information \& Management, 51(5), 568-578. doi:10.1016/j.im.2014.03.007

Chiu, C. M., Hsu, M. H., \& Wang, E. T. (2006). Understanding knowledge sharing in virtual communities: An integration of social capital and social cognitive theories. Decision Support Systems, 42(3), 1872-1888. doi:10.1016/j.dss.2006.04.001

Choo, C. W., \& de Alvarenga Neto, R. C. D. (2010). Beyond the ba: Managing enabling contexts in knowledge organizations. Journal of Knowledge Management, 22(6), 1408-1423.

Chow, W. S., \& Chan, L. S. (2008). Social network, social trust and shared goals in organizational knowledge sharing. Information \& Management, 45(7), 458-465. doi:10.1016/j.im.2008.06.007

Connelly, C. E., \& Kelloway, E. K. (2003). Predictors of employees' perceptions of knowledge sharing cultures. Leadership and Organization Development Journal, 24(5), 294-301. doi:10.1108/01437730310485815

Darvish, H., \& Nikbakhsh, R. (2010). Studying the relations of social capital factors with knowledge sharing: A case study at research department of IRIB. Transylvanian Review of Administrative Sciences, 6(31), 28-47.

Dawa, S., \& Namatovu, R. (2015). Social Networks and Growth of Female-Owned Ventures: A Sub-Saharan Africa Perspective. Journal of Developmental Entrepreneurship, 20(2), 1-19. doi:10.1142/S1084946715500090

Durbin, S. (2011). Creating knowledge through networks: A gender perspective. Gender, Work and Organization, 18(1), 90-112. doi:10.1111/j.1468-0432.2010.00536.x

Easterby-Smith, M., Lyles, M. A., \& Tsang, E. W. (2008). Inter-organizational knowledge transfer: Current themes and future prospects. Journal of Management Studies, 45(4), 677-690. doi:10.1111/j.1467-6486.2008.00773.x

Ekpe, I., Mat, N., \& Ekpe, M. (2015). Social Networks and Women Micro-Enterprise Performance: A Conceptual Framework. Mediterranean Journal of Social Sciences, 6(4), 360-366. doi:10.5901/mjss.2015.v6n4s3p360 
Ganguly, A., Talukdar, A., \& Chatterjee, D. (2019). Evaluating the role of social capital, tacit knowledge sharing, knowledge quality and reciprocity in determining innovation capability of an organization. Journal of Knowledge Management, 23(6), 1105-1135. doi:10.1108/JKM-03-2018-0190

Haeffele, S., Hobson, A., \& Storr, V. H. (2020). Coming Back from COVID-19: Lessons in Entrepreneurship from Disaster Recovery Research. Retrieved from George Mason University: https://papers.ssrn.com/sol3/ papers.cfm?abstract_id=3592966

Han, S. H., Yoon, S. W., \& Chae, C. (2020). Building social capital and learning relationships through knowledge sharing: a social network approach of management students' cases. Journal of Knowledge Management. 10.1108/ JKM-11-2019-0641

Hanson, S., \& Blake, M. (2009). Gender and entrepreneurial networks. Regional Studies, 43(1), $135-149$. doi:10.1080/00343400802251452

Heisig, P., \& Kannan, S. (2020). Knowledge management: Does gender matter? A systematic review of literature. Journal of Knowledge Management, 24(6), 1315-1342. doi:10.1108/JKM-08-2018-0472

Herrington, M., \& Kew, P. (2016). Global Entrepreneurship Monitor South African Report. Academic Press.

Inkpen, A. C., \& Tsang, E. W. K. (2016). Reflections on the 2015 Decade Award-Social Capital, Networks, and Knowledge Transfer: An Emergent Stream of Research. Academy of Management Review, 41(4), 573-588. doi:10.5465/amr.2016.0140

Inkpen, A. C., \& Tsang, E. W. K. (2005). Social Capital, Networks, and Knowledge Transfer. Academy of Management Review, 30(1), 146-165.

Jashapara, A. (2011). Knowledge Management. Pearson Education.

Jenkins-Guarnieri, M. A., Wright, S. L., \& Johnson, B. (2013). Development and validation of a social media use integration scale. Psychology of Popular Media Culture, 2(1), 38-50. doi:10.1037/a0030277

Jennex, M. E., \& Bartczak, S. E. (2015). A Revised Knowledge Pyramid. International Journal of Knowledge Management, 9(3), 19-30. doi:10.4018/ijkm.2013070102

Koonin, M. (2014). Validity and Reliability. In F. du Plooy-Cilliers, C. Davis, \& R. Bezuidenhout (Eds.), Research Matters (pp. 252-261). Juta.

Leana, C. R., \& Pil, F. K. (2006). Social capital and organizational performance: Evidence from urban public schools. Organization Science, 17(3), 353-366. doi:10.1287/orsc.1060.0191

Lefebvre, V. M., Sorenson, D., Henchion, M., \& Gellynck, X. (2016). Social capital and knowledge sharing performance of learning networks. International Journal of Information Management, 36(4), 570-579. doi:10.1016/j.ijinfomgt.2015.11.008

Levin, D. Z., \& Cross, R. (2004). The strength of weak ties you can trust: The mediating role of trust in effective knowledge transfer. Management Science, 50(11), 1477-1490. doi:10.1287/mnsc.1030.0136

Li, L. (2005). The effects of trust and shared vision on inward knowledge transfer in subsidiaries' intra- and interorganizational relationships. International Business Review, 14(1), 77-95. doi:10.1016/j.ibusrev.2004.12.005

Ma, W. W., \& Chan, A. (2014). Knowledge sharing and social media: Altruism, perceived online attachment motivation, and perceived online relationship commitment. Computers in Human Behavior, 39, 51-58. doi:10.1016/j.chb.2014.06.015

Majchrzak, A., Faraj, S., Kane, G. C., \& Azad, B. (2013). The Contradictory Influence of Social Media Affordances on Online Communal Knowledge Sharing. Journal of Computer-Mediated Communication, 19(1), 38-55. doi:10.1111/jcc4.12030

Maree, T. (2017). The social media use integration scale: Toward reliability and validity. International Journal of Human-Computer Interaction, 33(12), 963-972. doi:10.1080/10447318.2017.1301041

Mariotti, F. (2005). Conceptualizing inter-organizational learning: An emergent and process-based view of learning in organizational networks. Paper presented at the Sixth European Conference on Organizational Knowledge, Learning, and Capabilities, Waltham. 
Marouf, L. N., \& Khalil, O. E. (2015). The Influence of Individual Characteristics on Knowledge Sharing Practices, Enablers, and Barriers in a Project Management Context. International Journal of Knowledge Management, 11(1), 1-27. doi:10.4018/JJKM.2015010101

Massaro, M., Moro, A., Aschauer, E., \& Fink, M. (2019). Trust, control and knowledge transfer in small business networks. Review of Managerial Science, 13(2), 267-301. doi:10.1007/s11846-017-0247-y

Mc Manus, P., Ragab, M., Arisha, A., \& Mulhall, S. (2016). Review of Factors Influencing Employees' Willingness to Share Knowledge. Paper presented at the European Conference on Knowledge Management, Belfast, UK.

Muwanga-Zake, O., \& Herselman, M. (2017). An investigation into possibilities for implementation of a virtual community of practice delivered via a mobile social network for rural community media in the Eastern Cape, South Africa. South African Journal of Information Management, 19(1), 1-10. doi:10.4102/sajim.v19i1.730

Nahapiet, J., \& Ghoshal, S. (1998). Social capital, intellectual capital, and the organizational advantage. Academy of Management Review, 23(2), 242-266. doi:10.2307/259373

Nguyen, T. M., Nham, T. P., Froese, F. J., \& Malik, A. (2019). Motivation and knowledge sharing: A metaanalysis of main and moderating effects. Journal of Knowledge Management, 23(5), 998-1016. doi:10.1108/ JKM-01-2019-0029

Nieminen. (2005). Organizational Receptivity - Understanding the Inter- Organizational Learning Ability. Electronic Journal of Knowledge Management, 3(2), 107-118.

Ojong, N., Simba, A., \& Dana, L.-P. (2021). Female entrepreneurship in Africa: A review, trends, and future research directions. Journal of Business Research, 132, 233-248. doi:10.1016/j.jbusres.2021.04.032

Oke, D. (2013). The Effect of Social Network on Women Entrepreneurs in Nigeria: A Case Study of Ado-Ekiti Small Scale Enterprise. International Journal of Education and Research, 1(11).

Olanrewaju, A.-S. T., Hossain, M. A., Whiteside, N., \& Mercieca, P. (2020). Social media and entrepreneurship research: A literature review. International Journal of Information Management, 50, 90-110. doi:10.1016/j. ijinfomgt.2019.05.011

Pallant, J. (2010). SPSS survival manual: A step by step guide to data analysis using SPSS. Open University Press.

Paroutis, S., \& Al Saleh, A. (2009). Determinants of knowledge sharing using Web 2.0 technologies. Journal of Knowledge Management, 13(4), 52-63. doi:10.1108/13673270910971824

Parry, B. R., \& Gordon, E. (2021). The shadow pandemic: Inequitable gendered impacts of COVID-19 in South Africa. Gender, Work and Organization, 28(2), 795-806. doi:10.1111/gwao.12565 PMID:33230376

Powell, W., \& Snellman, K. (2004). The Knowledge Economy. Annual Review of Sociology, 30(1), 199-220. doi:10.1146/annurev.soc.29.010202.100037

Rhodes, J., Hung, R., Lok, P., Lien, B. Y. H., \& Wu, C. M. (2008). Factors influencing organizational knowledge transfer: Implication for corporate performance. Journal of Knowledge Management, 12(3), 84-100. doi:10.1108/13673270810875886

Ridgeway, C., \& Smith-Lovin, L. (1999). The Gender System and Interaction. Annual Review of Sociology, 25(1), 191-216. doi:10.1146/annurev.soc.25.1.191

Sekaran, U., \& Bougie, R. (2016). Research Methods for Buisness: A Skill Building Approach. John Wiley \& Sons.

Shanmuga, P., \& Sakthi, D. (2015). Social Media a Tool for Economic Empowerment of Women. International Journal of Applied Research, 1(5), 157-160.

Spender, J.-C., Corvello, V., Grimaldi, M., \& Rippa, P. (2017). Startups and open innovation: A review of the literature. European Journal of Innovation Management, 2(1), 4-30. doi:10.1108/EJIM-12-2015-0131

Statistica. (2021). Distribution of Facebook users in South Africa as of April 2021, by age group. Retrieved from https://www.statista.com/statistics/1028389/facebook-user-share-in-south-africa-by-age/

Tohidinia, Z., \& Mosakhani, M. (2010). Knowledge sharing behaviour and its predictors. Industrial Management \& Data Systems, 110(4), 611-631. doi:10.1108/02635571011039052 
Tsai, W., \& Ghoshal, S. (1998). Social capital and value creation: The role of intrafirm networks. Academy of Management Journal, 41(4), 464-476.

Upton, L., Broming, E. J., \& Upton, R. L. (2015). Research on women entrepreneurs' social networks. National Women's Business Council.

Usoro, A., Sharratt, M. W., Tsui, E., \& Shekhar, S. (2007). Trust as an antecedent to knowledge sharing in virtual communities of practice. Knowledge Management Research and Practice, 5(3), 199-212. doi:10.1057/ palgrave.kmrp.8500143

van Blokland, A. B. (2018). Why Female Entrepreneurs Should Join Women's Networks. Retrieved from https://www.forbes.com/sites/anettebvanblokland/2018/10/18/why-female-entrepreneurs-should-join-womensnetworks/?sh=25fb494e2a13

Van Den Hooff, B., \& De Ridder, J. A. (2004). Knowledge sharing in context: The influence of organizational commitment, communication climate and CMC use on knowledge sharing. Journal of Knowledge Management, 8(6), 117-130. doi:10.1108/13673270410567675

Van den Hooff, B., Elving, W., Meeuwsen, J. M., \& Dumoulin, C. (2003). Knowledge sharing in knowledge communities. Paper presented at the Communities and technologies. doi:10.1007/978-94-017-0115-0_7

Van Der Meer, R. (2014). Knowledge Sharing in Inter-organisational Collaborations (PhD Thesis). Deakin University Swinburne.

van Wijk, R., Jansen, J. J. P., \& Lyles, M. L. (2008). Inter- and Intra-Organizational Knowledge Transfer: A Meta-Analytic Review and Assessment of its Antecedents and Consequences. Journal of Management Studies, 45(4), 830-853. doi:10.1111/j.1467-6486.2008.00771.x

Warner, R. M. (2012). Applied Statistics: From Bivariate Through Multivariate Techniques (Vol. 2). SAGE Publications Inc.

Paula Hall is currently a lecturer and developer at the Independent Institute of Education's Varsity College. She has over 30 years of experience in the Information Technology profession. Paula is a PhD student at the University of KwaZulu Natal, South Africa, conducting research on women in Al. She completed her Master's degree at the same institution on female networks and knowledge management.

Debbie Ellis is an Associate Professor in Marketing in the School of Management, IT and Governance, UKZN. She has a PhD from KTH Royal Institute of Technology, Sweden and a Masters in Business Science from the University of Cape Town, South Africa. Debbie has 30 years of teaching, supervision, and research experience. Her work has been published in the International Journal of Consumer Studies, Young Consumers, Business Horizons, the International Review of Retail, Distribution and Consumer Research, the South African Journal of Business Management, and the Southern African Business Review, among others. Her primary areas of research interest include eco-consumption, social marketing, young consumers, consumer knowledge, knowledge management, female networks, strategic marketing, and positioning.

Brian McArthur holds a BSc in Computer Science, an MA in English, an MBA and a PhD in Education (Information Systems Research Methodology Curricula). He is currently an Associate Professor at the University of KwaZuluNatal where he teaches Research Methodology in the discipline of Information Systems and currently serves as the acting Deputy Vice-Chancellor for the College of Law and Management Studies. 